\title{
Léon-Joseph Suenens, Mémoires sur le Concile Vatican II
}

Leuven, Peeters, coll. « Instrumenta Theologica », 2014, 68 p., édités et annotés par Werner Van Laer. Préface du Cardinal Godfried Danneels. Introduction par Leo Declerck

\section{Agnès Desmazières}

\section{(2) OpenEdition}

12 Journals

\section{Édition électronique}

URL : http://journals.openedition.org/assr/28354

DOI : $10.4000 /$ assr.28354

ISSN : $1777-5825$

Éditeur

Éditions de l'EHESS

\section{Édition imprimée}

Date de publication : 31 décembre 2016

Pagination : 395

ISSN : 0335-5985

\section{Référence électronique}

Agnès Desmazières, "Léon-Joseph Suenens, Mémoires sur le Concile Vatican II 》, Archives de sciences sociales des religions [En ligne], 176 | octobre-décembre 2016, mis en ligne le 20 juillet 2017, consulté le 24 septembre 2020. URL : http://journals.openedition.org/assr/28354 ; DOI : https://doi.org/10.4000/ assr.28354

Ce document a été généré automatiquement le 24 septembre 2020.

(c) Archives de sciences sociales des religions 


\section{Léon-Joseph Suenens, Mémoires sur le Concile Vatican II}

Leuven, Peeters, coll. « Instrumenta Theologica », 2014, 68 p., édités et annotés par Werner Van Laer. Préface du Cardinal Godfried Danneels. Introduction par Leo Declerck

\section{Agnès Desmazières}

\section{RÉFÉRENCE}

Léon-Joseph Suenens, Mémoires sur le Concile Vatican II, Leuven, Peeters, coll.

«Instrumenta Theologica », 2014, 68 p., édités et annotés par Werner Van Laer. Préface du Cardinal Godfried Danneels. Introduction par Leo Declerck

1 Ce court volume est une édition critique du manuscrit des « Mémoires sur le Concile Vatican II » du cardinal Leo Jozef Suenens, archevêque de Malines et acteur majeur du Concile. Il ne s'agit pas du premier récit publié de son expérience conciliaire, le cardinal belge s'étant exprimé en des occasions variées sur sa contribution au Concile. Parus à titre posthume, près de dix ans après la mort de Suenens, ces mémoires constituent toutefois une source importante pour l'histoire du Concile Vatican II en ce qu'ils en représentent le témoignage le plus ancien.

2 Ce texte a un statut particulier parmi les nombreux journaux et mémoires rédigés par les protagonistes du Concile. Il n'a pas été rédigé au jour le jour, pendant le Concile, à la différence des journaux de Congar et de Lubac ou encore des notes du Père Chenu par exemple, mais a posteriori, dans les mois qui suivent la clôture de Vatican II. Suenens porte ici un regard rétrospectif sur sa participation conciliaire, sous la lumière optimiste de l'immédiat après-Concile. De caractère privé, il est toutefois guidé par le clair dessein de réunir un matériau préparatoire en vue d'un usage public ultérieur. Il servira effectivement de base à la rédaction de Souvenirs et espérances, publié, en 1991, du vivant même du cardinal. 
3 L'intention qui préside à ces « Mémoires » est de fournir un éclairage personnel et, en ce sens, partial et engagé, sur le Concile. Leo Declerck en signale, dans l'introduction, la valeur et les limites. Sa valeur réside avant tout dans le jugement que Suenens porte sur «certains acteurs du Concile» (p. XII). Encore faut-il relever certains correctifs apportés à ce propos dans Souvenirs et espérances. Declerck n'en gomme pas les limites : manque de "souci de la précision historique » et «tendance à majorer son propre rôle" (p.XI-XII). Un croisement est dès lors nécessaire avec d'autres sources archivistiques, en premier lieu les archives mêmes du cardinal Suenens (Cahiers de la Revue théologique, 31, 1998) et celles du Concile Vatican II, conservées dans les Archives secrètes du Vatican.

4 Au fur et à mesure de son récit, Suenens se montre plus concis, moins prolixe en détails. Alors qu'il consacre près de vingt pages à la seule phase préparatoire, il ne lui en faut plus que cinq pour narrer la quatrième et dernière session conciliaire. La raison tient sans doute à la valeur programmatique qu'il accorde à sa contribution dans la phase préparatoire, à commencer par les vœux qu'il adresse en réponse à la demande de consultation du Pape Jean XXIII. Dès cette époque, l'on note l'intérêt majeur du cardinal pour le thème de l'apostolat des laïcs, conçu dans un sens large, non limité à la seule Action catholique. L'élément le plus décisif de cette phase préparatoire consiste toutefois dans les liens étroits tissés avec Jean XXIII, même si l'influence que son plan du Concile exerce sur le Pape a été relativisée.

5 Les différentes interventions du cardinal Suenens au Concile constituent la trame principale de son récit. Si, à propos des deux premières sessions, il s'étend sur le contexte plus général et, spécialement, sur ses responsabilités dans la gouvernance du Concile, sa narration des sessions suivantes se limite à un commentaire de ses interventions dans l'aula conciliaire. Le discours du 4 décembre 1962, à la fin de la première session, où il expose lui-même son plan du Concile, constitue l'élément central de cette trame. Ses interventions, dans la suite, concernent avant tout les deux futures constitutions Lumen gentium et Gaudium et spes. Pour la première, l'on notera en particulier sa contribution décisive au rétablissement du diaconat permanent. À propos de la seconde, c'est la question de la contraception, où il se trouve en désaccord avec Paul VI, qui mobilise son attention. L'on relèvera aussi sa sensibilité à la cause des femmes, exprimée en deux occasions, d'abord concernant les laïcs, puis concernant les religieuses, et le rôle que ces interventions ont joué en faveur de la participation des femmes, laïques et religieuses, aux travaux du Concile comme auditrices.

Relevons le caractère extrêmement original de l'essai de relecture réalisé par le cardinal Suenens. La mise en contexte des interventions qu'il propose est très utile pour l'historien, en dépit de son caractère personnel et subjectif. L'introduction et les notes de l'ouvrage, qui se fondent sur des études historiques du manuscrit, préliminaires à sa publication, sont un précieux apport pour une lecture critique, tout à fait stimulante. 